\title{
Exposé or misconstrual? \\ Unresolved issues of authorship and the authenticity of GW Stow's 'forgery' of a rock art painting
}

MARGUERITE PRINS ${ }^{1}$

\begin{abstract}
George William Stow (1822-1882) is today considered to have been one of the founding fathers of rock art research and conservation in Southern Africa. He arrived from England in 1843 and settled on the frontier of the Eastern Cape where he gradually started specializing in geological exploration, the ethnological history of the early peoples of the subcontinent and the rock art of the region.

By the 1870s he was responsible for the discovery of the coalfields in the Vaal Triangle of South Africa.

In recent years Stow's legacy has been the subject of academic suspicion. Some rock art experts claim that he made himself guilty of 'forgery'. In the article the authors argues in favour of restoring the status of Stow by pointing to the fact that two mutually exclusive interpretational approaches of rock art, than it is about an alleged forgery, are at the heart of the attempts at discrediting his work. In the process, irreparable and undeserving harm has been done to the name of George William Stow and his contribution to rock art research and conservation in South Africa.
\end{abstract}

Key words. GW Stow, rock art, shamanistic approach, geology, archaeology, heritage conservation.

\section{Introduction}

For the researcher engaged in a study of the rock engravings of Redan near Vereeniging, it is usually inevitable to come across the name of George William Stow (1822-1882). Stow discovered the rich coal fields in the Vaal area that would lead to the formation of a vast coal empire and the establishment of the industrial city of Vereeniging. ${ }^{2}$ Stow also laid the foundation for rock art research and conservation in South Africa. Twenty-three years after his death his treatise The native races

1 Dr Marguerite Prins, completed a PhD in history at North-West University in 2005. It was titled The primordial circle: the prehistoric rock engravings of Redan, Vereeniging. An earlier draft of this article was presented at a conference of the South African Association of Art Historians, at the University of Stellenbosch in September 2003.

2 R Mendelsohn, Sammy Marks: 'The uncrowned king of the Transvaal' (David Philip, Cape Town, 1991), pp. 11-15. 
of South Africa was published posthumously. ${ }^{3}$ The publication was illustrated with four copies of rock art including a copy entitled 'Bushman disguised as ostrich'. Recently Stow's name was resurrected, not to honour his many achievements, but to 'expose' him as a liar and a cheat and to accuse him of deliberately forging the ostrich copy for his own gain. A close scrutiny of Stow's voluminous correspondence, both published and unpublished and of his copies, reveals a number of inconsistencies that seriously weaken, if not refute, the claim that he perpetrated an intentional hoax. A more serious repercussion of this allegation is that it has impacted directly on how Stow's contribution, both his copies and his written treatise, are perceived and utilised by researchers.

\section{The man and his times}

Stow emigrated from England and settled on the turbulent Eastern Cape border in 1843, where he rapidly became known as a skilled amateur geologist. In the course of his geological explorations he developed an interest in the Bantu-speaking and Khoisan peoples, and began documenting their histories and customs, and making copies of their rock paintings. Stow started copying rock art in 1867 . He wanted to use it as a visual clue to their customs and manners. ${ }^{4}$ In 1879, 36 years after settling in South Africa, ${ }^{5}$ he started writing what was to become one of the earliest contributions on the history of the Khoisan peoples of southern Africa.

Stow was the quintessential autodidact, completely self-taught in the three fields that would bring him fame, geology, ethnology and the study of rock art. He pursued these disciplines simultaneously. He travelled in an ox-wagon, covered thousands of kilometres, frequently into unexplored terrain, worked for long periods without remuneration and suffered extreme physical deprivation. ${ }^{6}$ He conducted interviews with the Bushmen he encountered, and became an indefatigable recorder of their art, and a passionate spokesman for the preservation of Bushman art and culture. On occasion he explained:

One thing is certain, if I am spared I shall use every effort to secure all the paintings in the state that I possibly can, that some record may be kept (imperfect as it must necessarily be ...). I have never lost an opportunity during that time of rescuing from total obliteration the memory of their wonderful

3 GW Stow, The native races of South Africa: a history of the intrusion of the Hottentots and Bantu into the hunting grounds of the Bushmen, the aborigines of the country (Edited by G. McCall Theal. Swann Sonnenschein \& Co. Ltd, London, [1905], [reprinted 1906], 1910).

4 D Lewis-Williams, Stories that float from afar: ancestral folklore of the San of Southern Africa, (Second printing, (first 2000), David Philip, Cape Town, 2002), p. 21; RB Young, The life and work of George William Stow, (Longmans, Green, London, 1908), p. 18.

5 GW Stow, The native races of South Africa: a history of the intrusion of the Hottentots and Bantu into the hunting grounds of the Bushmen, the aborigines of the country, (Edited by G. McCall Theal, Swann Sonnenschein \& Co. Ltd, London, 1910), p. 2.

6 RB Young, The life and work of George William Stow. (Longmans, Green, London, 1908), pp. 7-11. 
artistic labours, at the same time buoying myself up with the hope that by so doing a foundation might be laid to a work that might ultimately prove to be of considerable importance and value to the student of the earlier races of mankind. ${ }^{7}$

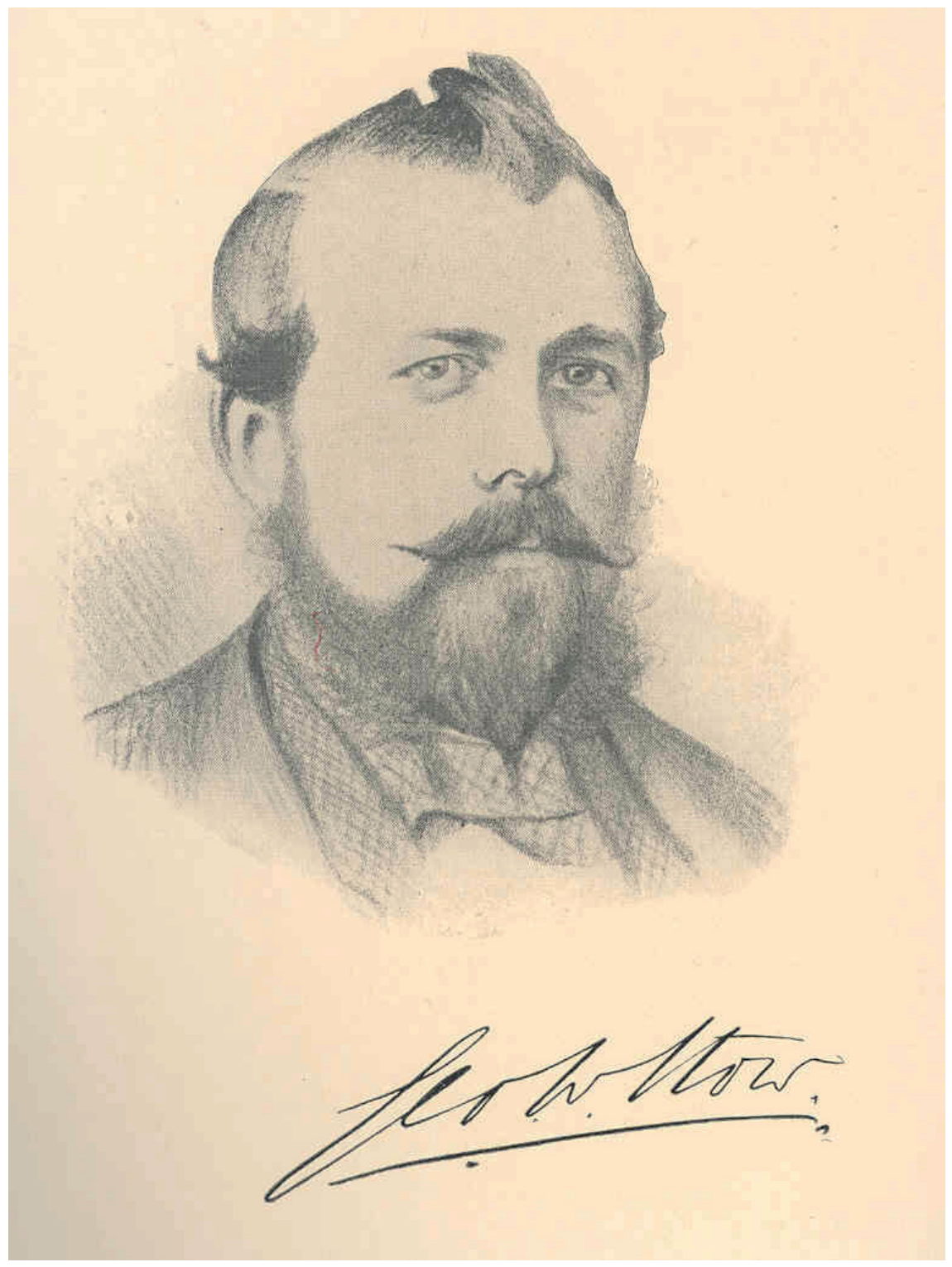

\section{Illustration 1: GW Stow. Source: Young}

7 GW Stow - Lucy Lloyd, 4 June 1877, in K Schoeman, A debt of gratitude: Lucy Lloyd and the 'Bushman work' of GW Stow, (Cape Town: South African Library, Cape Town, 1997), p. 73. 
Judged by today's exacting standards, Stow's copy method appears somewhat unorthodox. It consisted of two distinct stages. On site he took a few basic measurements, transferred these to rough paper, drew in the images free-hand, made pencil annotations of the colours and collected pigment samples in situ. The final copy was made by tracing and scoring through the images, transferring these to cartridge paper and adding colour washes. It is also widely known that many of his copies are in fact compilations consisting of the selection and omission of images from different parts of the rock face, to form a single composition. ${ }^{8}$ This practice was not considered unusual or fraudulent. It was dictated by Stow's extreme sense of urgency to record as much of the art as possible in order to preserve it for posterity. As a result of the acute shortage of paper he invariably experienced in the veld ${ }^{9}$ he was also anxious to make each copy as 'representative' as possible.

In 1874, while engaged in geological reconnaissance for the Legislature of Griqualand West (North West Province), Stow began corresponding with the philologist, W.H.I. Bleek, Curator of the Grey Collection in Cape Town and renowned scholar of the Bushman language and culture. As a result of Bleek's interest in the Bushman culture, a number of interested individuals had been sending him copies of the rock art. ${ }^{10}$ Stow subsequently sent him a portfolio containing 72 of his copies of rock paintings and engravings. In a letter to Bleek he expounded his narrative view of the art:

Some may have a mythological character but others are certainly historical paintings ... These are frequently representations of battles - huntings and dances in which the Bushmen are represented wearing the different disguises they are known to adopt on such occasions - but which European eyes when they see representations of men enveloped in skins with beaks or birds' heads - or with tails of iguanas and other animals fastened around their wrists, make them believe they must have a mythological or fabulous meaning, instead of representing the manners and customs of the Bushmen as they really were. ${ }^{11}$

Bleek did not dispute this interpretation, and in his second official report, published the following year, he acknowledged these copies as a 'magnificent collection' and added that their publication

cannot but effect a radical change in the ideas generally entertained with regard to the Bushmen and their mental condition. An inspection of these pictures and their explanation by Bushmen has only commenced; but it promises some valuable results and throws light upon many things hitherto unintelligible. ${ }^{12}$

8 GW Stow and D.F. Bleek, Rock paintings in South Africa from parts of the Eastern Province and Orange Free State, (Methuen, London, 1930), p. xxvi.

9 Ibid., p. xxvii.

$10 \mathrm{~K}$ Schoeman, A debt of gratitude: Lucy Lloyd and the 'Bushman work' of GW Stow, p. 42.

11 McGreggor Museum Depot MMKD 2650/1. Correspondence: GW Stow - L. Lloyd, 14 December 1874.

12 K Schoeman, A debt of gratitude: Lucy Lloyd and the 'Bushman work' of GW Stow, p. 42. 
This promising correspondence was cut short by Bleek's sudden death on 17 August $1875,{ }^{13}$ but was continued by his sister-in-law and collaborator Lucy Lloyd. ${ }^{14}$ Lloyd was responsible for much of the interviews, transcripts and translations of the verbatim accounts delivered by a number of Bushmen, residing with Bleek in his home. ${ }^{15}$ Isolated in the field, Lucy Lloyd became Stow's confidante and mentor, and he kept her informed of every step of the progress he was making both with his written treatise, and his copies of the rock art. In the course of his travels the idea came to him to use his copies to illustrate his written treatise.

Stow did not live to see his text or his copies published. While in the field he heard the heartbreaking news that due to its great length, the publisher John Murray of London was unable to publish his treatise. ${ }^{16}$ He died 18 months later (presumably of a heart attack). In spite of her own precarious financial situation, Lucy Lloyd purchased the remaining copies that were in the possession of Stow's widow. Furthermore, regardless of ill health, Lucy Lloyd persevered for many years in trying to find a publisher. She eventually enlisted the help of the historian G. McCall Theal, and The native races of South Africa was finally published in 1905, illustrated with a copy of 'Bushman disguised as ostrich'. ${ }^{17}$

\section{The case against Stow}

In 1994, more than 100 years after Stow's death, an article 'The mystery of the blue ostriches' appeared in the prestigious publication African Studies. ${ }^{18}$ It was co-authored by three prominent academics, Thomas A. Dowson, Phillip V. Tobias and J. David Lewis-Williams. This article was preceded by a provisional exposé earlier. ${ }^{19}$ In the 1994 article, it is alleged that Stow perpetrated an intentional hoax, in order to support his 'firm belief that the rock paintings faithfully chronicled the customs and hunting activities of the Bushmen'. ${ }^{20}$ The authors argue that the blue os-

13 D Lewis-Williams, Stories that float from afar: ancestral folklore of the San of Southern Africa, (Second printing, (first 2000),David Philip, Cape Town, 2002), p. 22.

14 D Lewis-Williams, Stories that float from afar: ancestral folklore of the San of Southern Africa, (Second printing, (first 2000),David Philip, Cape Town, 2002), p. 24.

15 E. Eberhard, "Wilhelm Bleek and the founding of Khoisan research", in J. Deacon \& TA Dowson (eds), Voices from the past: IXam Bushmen and the Bleek and Lloyd collection, (Witwatersrand University Press, Johannesburg, 1996), p. 54.

16 Ibid., p. 54.

17 GW Stow, The native races of South Africa, (Swan \& Sonnenschein, London, (1905) 1964), p. 82.

18 TA Dowson, PV Tobias and JD Lewis-Williams, "The mystery of the blue ostriches: clues to the origin and authorship of a supposed rock painting" in African Studies, 53(1), 1994, pp. 3-38.

19 TA Dowson, "The making of the 'blue ostriches': further light on a scientific fraud" in South African Journal of Science, 89, 1993, pp. 360-361.

20 TA Dowson, PV Tobias and JD Lewis-Williams, "The mystery of the blue ostriches: clues to the origin and authorship of a supposed rock painting" in African Studies, 53(1), 1994, p. 4. 
triches (as the copy 'Bushman disguised as ostrich' became known) is not copied from an original rock painting, but is derived from an illustration in Robert Moffat's Missionary labours and scenes in South Africa. ${ }^{21}$ This is substantiated with an illustration. ${ }^{22}$ The authors believe that Stow reversed the illustration left to right and that he deliberately omitted some of the images to make it appear more like a genuine rock painting. Apart from a superficial resemblance between the composition of the blue ostriches and Moffat's illustration, these allegations remain unproven and speculative.

As further evidence the authors argue that no field copy has ever been located, but that an Indian ink copy in possession of the Rock Art Research Unit of the University of the Witwatersrand, ${ }^{23}$ shows that the deeply curved neck of one of the ostriches, is a deliberate falsification. Moreover, that the blue colour of the ostriches is unusual (hence the name 'blue ostriches'), and that the composition suggests 'a sense of European perspective'. ${ }^{24}$ The authors assert that the original rock painting has never been located, in spite of Stow's daughter testifying in the 1930s to Dorothea Bleek that she recalled visiting such a cave with her father. Miss Stow's testimony is questioned and rejected, implicating her together with her father. ${ }^{25}$

Stow (and a number of early travellers) are brought into further discredit by questioning the validity of the ostrich hunting strategy of the Bushmen. In the article the authors argues that there have been frequent borrowings amongst early writers, ${ }^{26}$ and conclude that:

As further evidence the authors argue that no field copy has ever been located, but that an Indian ink copy in possession of the Rock Art Research Unit of the University of the Witwatersrand, ${ }^{27}$ shows that the deeply curved neck of one of the ostriches, is a deliberate falsification. Moreover, that the blue colour of the ostriches is unusual (hence the name 'blue ostriches'), and that the composition suggests 'a sense of European perspective'. ${ }^{28}$ The authors assert that the original rock painting has never been located, in spite of Stow's daughter testifying in the

21 R Moffat, Missionary labours and scenes in Southern Africa: twenty-three years an agent of the London Missionary Society in that continent, (John Snow, Paternoster-Row, London, 1842).

22 TA Dowson, PV Tobias and JD Lewis-Williams, "The mystery of the blue ostriches: clues to the origin and authorship of a supposed rock painting" in African Studies, 53(1), 1994, Fig. 5.

23 Now known as the Rock Art Research Institute.

24 TA Dowson, PV Tobias and JD Lewis-Williams, "The mystery of the blue ostriches: clues to the origin and authorship of a supposed rock painting" in African Studies, 53(1), 1994, p. 9.

25 Ibid., pp. 9, 23.

26 Ibid., p. 11.

27 Now known as the Rock Art Research Institute.

28 TA Dowson, PV Tobias and JD Lewis-Williams, "The mystery of the blue ostriches: clues to the origin and authorship of a supposed rock painting" in African Studies, 53(1), 1994, p. 9. 
1930s to Dorothea Bleek that she recalled visiting such a cave with her father. Miss Stow's testimony is questioned and rejected, implicating her together with her father. ${ }^{29}$

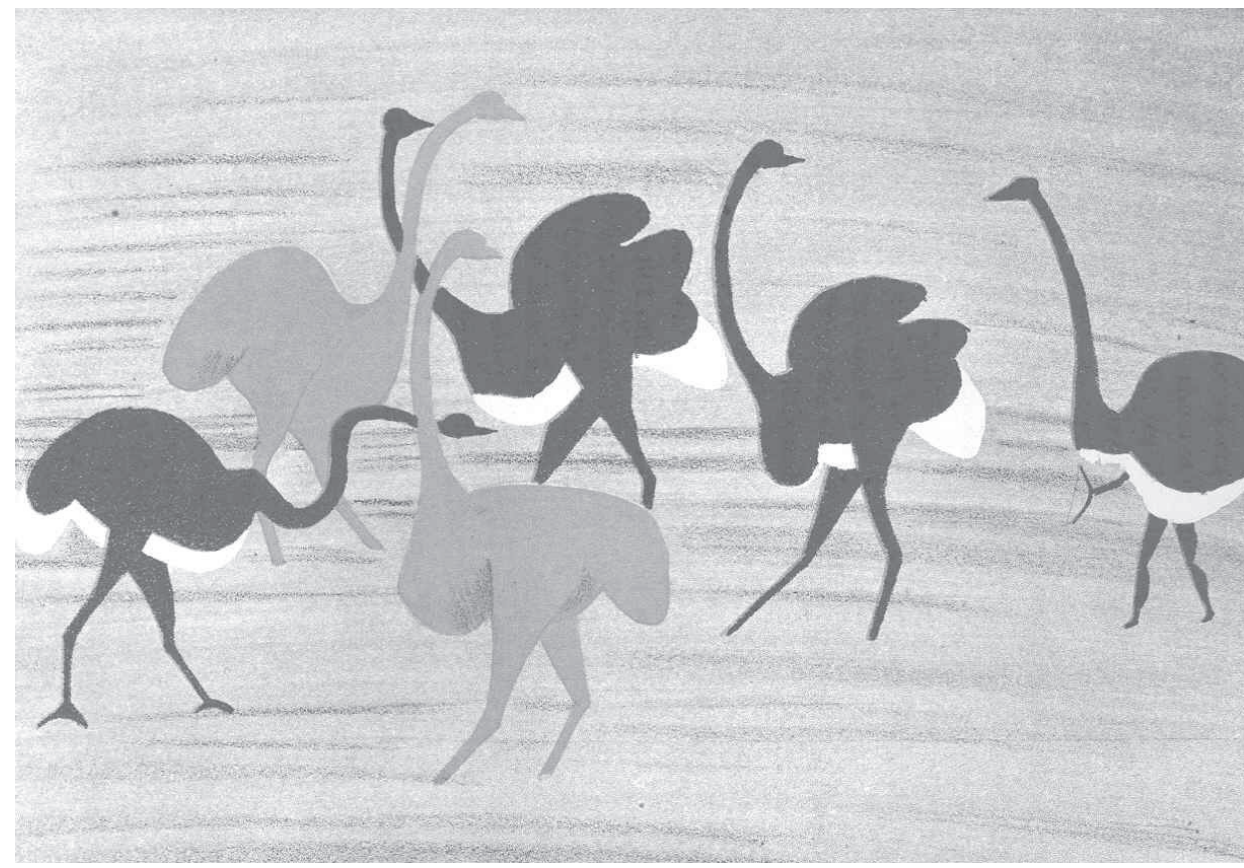

\section{Illustration 2: 'Bushman disguised as Ostrich' now called 'The blue ostriches'. Source: GW Stow (1905), Opposite} p. 82.

Stow (and a number of early travellers) are brought into further discredit by questioning the validity of the ostrich hunting strategy of the Bushmen. In the article the authors argues that there have been frequent borrowings amongst early writers, ${ }^{30}$ and conclude that:

the supposed employment by Bushmen of ostrich disguises, and their depiction of some other types of hunting disguises have been seriously questioned.

They believe that the therianthropes (half-men/half-beasts) frequently depicted in rock paintings do not portray hunting and dancing disguises, but the trance experience of the shaman:

The art is now believed to have been principally, though not necessarily exclusively, associated with the activities of shamans who entered trance to cure the sick, change the weather, go on out-of-body travel, control the movements of animals, and transform themselves into animals. ${ }^{31}$

29 Ibid., pp. 9, 23.

30 Ibid., p. 11.

31 Ibid., p. 8. 
This overt reference to the trance hypothesis / shamanistic approach ${ }^{32}$ is a clear indication of the theoretical stance of the authors.

In their zeal to convince the reader of the validity of the trance hypothesis as opposed to the speciousness of Stow's narrative approach, parallels are drawn with the infamous Piltdown hoax:

Acceptance of false evidence can have the unfortunate consequence that genuine advances are thereby marginalised and their acceptance delayed, as were Raymond Dart's claims for the Taung skull .... ${ }^{33}$

The authors are at pains to point out that:

once a culprit has been identified, the rest of his or her work must be subjected to more critical scrutiny. ${ }^{34}$

Researchers are cautioned to practice extreme caution when interpreting rock art:

The uncritical citing of Stow's writings to interpret rock paintings would therefore run the risk of circularity. ${ }^{35}$

In order to unravel the mystery of the blue ostriches, a close reading of all available correspondence was undertaken. This included the extensive correspondence that passed between Stow and Lucy Lloyd over a period of five years, introduced and edited by Karel Schoeman (1997), and a number of unpublished letters obtained from the archives of the McGregor Museum. The latter includes a brief but significant correspondence between Stow and W.H.I. Bleek, and more recent correspondence dating from the 1940s between Dorothea Bleek and Maria Wilman. This correspondence was augmented by studying Stow's copies, and by comparing the two printed versions of the blue ostriches. The latter led to a startling discovery.

\section{The correspondence}

In his correspondence Stow frequently expressed concern regarding fraudulent copies. Even at this early date and given the low esteem that Bushmen were generally held in by the majority of colonists and travellers, there was nevertheless a demand for copies of their art, and copies were being duplicated and even fabricated, and sent back to England. ${ }^{36}$ After entrusting his portfolio of copies to Bleek in 1875, Stow sought some reassurance from him regarding their safety and confidentiality.

32 See also JD Lewis-Williams, Believing and seeing: symbolic meanings in southern San rock paintings, (Academic Press, London, 1981); JD Lewis-Williams, and TA Dowson, Images of power: understanding Bushman rock art, (Johannesburg: Southern Books, Johannesburg, 1989).

33 TA Dowson, PV Tobias and JD Lewis-Williams, "The mystery of the blue ostriches: clues to the origin and authorship of a supposed rock painting" in African Studies, 53(1), 1994, p. 7.

34 Ibid., p. 23)

35 Ibid., p. 32.

36 Referred to as 'home' in the correspondence. 
I sent away from here, sometime back my large portfolio of Bushman drawings ... But since then I have not heard a word upon the subject and I have been nervous in consequence ever since, as the work of years might be destroyed in two or three hours by a thunder storm ... I trust they were not disturbed before they reached you. My dear Sir, I trust implicitly to the strong pledge you gave me that they should only be seen by a few trustworthy gentlemen; and no one was to be allowed to make any notes or copies, on any context whatever. ${ }^{37}$

Stow's concern was shared by Sir Bartle Frere, Governor of the Cape Colony, who was allowed to inspect Stow's copies in Lucy Lloyd's possession including copies sent by other copyists:

(I)t appeared from what Mr Trimen told me that H.E. had thought that there might be pictures not belonging to your collection (but equally good) of which one or two specimens might have been sent home in Mr Trimen's care, to give the publishers an idea of the kind of work which would be needed when the time for reproduction came .... ${ }^{38}$

Stow responded by sending a detailed list of the specimen copies that he wished to be presented to the publisher:

From what I remember, No. 8 from the mountains N.W. of Komani would be a good representative one, 'Advance of women in masquerading dresses'; also no. 16, 'Bushman tribes in wild boar hunting', from Dordrecht, Stormberg; no. 23 from Lower Imvani, 'Lions attacking elands', and no. 40 from Madura's Cave in the banks of the 'Ca-'ca-du, 'Group of bucks (antelope trekking)'. These with the chippings, no. 4, the one partially shaded, will, I think, form specimen cartoons enough. I will however, leave it to your judgement.... ${ }^{39}$

It is significant that Stow did not include 'Bushman disguised as ostrich' in this list; his suggested list included only one hunting/dancing disguise, 'Advance of women in masquerading dresses'. ${ }^{40}$ In the same letter Stow requested Lucy Lloyd to write descriptive notes of the 'drawings' that would be dispatched to England,

(S)o that I can embody it into the work among the others if they do not return, in time. ${ }^{41}$

This is a reference both to Stow's unorthodox modus operandi of incorporating 'representative' images freely into his copies, and to the unfinished, field copies that had been included in the portfolio of copies he had sent to Bleek in 1875: He pointed out to her:

(T)he difficulty now is how to get it from here to Cape Town safely ... as to save time I shall have to send a number in an unfinished state - and I would

37 McGregor Museum Depot MMKD 2656/3. Correspondence: GW Stow to Bleek, 18 May 1875. Emphasis added).

38 Correspondence: L Lloyd to Stow, 15 August 1878 in K Schoeman, A debt of gratitude: Lucy Lloyd and the 'Bushman work' of GW Stow, p. 79. Emphasis added.

39 GW Stow - Lucy Lloyd, 21 October 1878 in K Schoeman, A debt of gratitude: Lucy Lloyd and the 'Bushman work' of GW Stow, p. 90. Emphasis added.

40 GW Stow, and DF Bleek, Rock paintings in South Africa from parts of the Eastern Province and Orange Free State, (Methuen, London, 1930), Plate 13.

41 Correspondence: GW Stow to Lucy Lloyd, 21 October 1878, K Schoeman, A debt of gratitude: Lucy Lloyd and the 'Bushman work' of GW Stow, p. 91. 
therefore refine these again after you have studied them. ${ }^{42}$

Negotiations with the publisher John Murray of London commenced in 1880, and Stow reiterated that due to circumstances, he was sending unfinished field copies:

I have been engaged for the last six or seven weeks along the banks of the Vaal inspecting the Free State coal deposits. The same cause has obliged me to send you my original sketches for the illustration of this portion. My intention was to have reduced them to the size of a page, and to have shaded and tinted them in their proper colours, but as a travelling wagon is my only residence while engaged in field work, and a series of sandstorms intermitting with rain and snow having continued for fourteen or sixteen days and still showing no signs of abating, I have found it impossible to carry out. ${ }^{43}$

Murray was unable to publish Stow's manuscript, and Stow died 18 months later. The unfinished field copies were not returned to Lucy Lloyd immediately:

I have already been endeavouring for some time to ascertain their whereabouts from Miss Frere (who kindly took them home for Mr Stow), but hitherto unsuccessful. ${ }^{44}$

After Stow's death, Lucy Lloyd immediately made arrangements to purchase all of Stow's copies for future publication:

(A)nd then they might be published (always, of course, as Mr Stow's work) with the mass of material with regard to the Bushmen which has been accumulated by the late Dr. Bleek and myself. ${ }^{45}$

Dowson et al. state that the

numbering of the second part of the collection suggests that the blue ostrich copy was already in sequence before the copies reached Cape Town.... ${ }^{46}$

They maintain that Stow deliberately held the 'forged' copy back as part of a numbered sequence, in order to include it in a future publication. ${ }^{47}$

The unpublished correspondence has now revealed that the numbering of this second batch of copies was in fact not done by Stow. After his sudden death, his affairs were understandably in complete disarray, and his personal effects, including his copies, were scattered in various places. Before dispatching the second batch of copies to Lucy Lloyd, Fanny Stow

42 Correspondence: GW Stow - Bleek, 23 January 1875, McGregor Museum Depot MMKD 2650/2, emphasis added)

43 Correspondence: GW Stow - John Murray, 6 September 1880 in K Schoeman, A debt of gratitude: Lucy Lloyd and the 'Bushman work' of GW Stow, p. 106.

44 Correspondence: L Lloyd - Fanny Stow, 24 July 1882 in K Schoeman, A debt of gratitude: Lucy Lloyd and the 'Bushman work' of GW Stow, p. 114.

45 Correspondence: L Lloyd to Fanny Stow, 24 July 1882, K Schoeman, A debt of gratitude: Lucy Lloyd and the 'Bushman work' of GW Stow, p. 110.

46 TA Dowson, PV Tobias and JD Lewis-Williams, "The mystery of the blue ostriches: clues to the origin and authorship of a supposed rock painting" in African Studies, 53(1), 1994, p. 25.

47 TA Dowson, PV Tobias and JD Lewis-Williams, "The mystery of the blue ostriches: clues to the origin and authorship of a supposed rock painting" in African Studies, 53(1), 1994, p. 35. 
numbered them herself, later to be re-numbered by Dorothea Bleek:

There are two sets of numbers on the copies. The larger ones in brackets are old ones. I fancy Mrs Stow must have put them on haphazard for they jump about from one locality to another. The smaller ones without brackets are mine, which I put on when I had ordered the copies according to localities. ${ }^{48}$

This letter also reveals that a number of copies that had been left in the care of Stow's friend, C.S. Orpen, were not recovered. Dorothea Bleek noted:

As to Stow's tracings my aunt bought all the paintings and tracings from Mrs Stow after Stow's death ... She said there were some missing ... She never did find them, because they evidently did not know of the box or boxes in the Free State. ${ }^{49}$

After 1882 Lucy Lloyd was the sole owner and custodian of Stow's copies. They were housed in the Bleek home in Cape Town, together with the collection of copies received from other copyists from time to time. The number of publishers approached after 1882 is not known, but in 1905 , Swan and Sonnenschein of London finally published The native races of South Africa. It was illustrated with a number of Stow's copies, including the now infamous copy, 'Bushman disguised as ostrich'. ${ }^{50}$

\section{Clues}

Lucy Lloyd died in 1914 and the copies were inherited by her niece Dorothea Bleek, then 14 years old, and also destined to become a respected authority on the Bushman language and culture. ${ }^{51}$ The bulk of the copies remained unpublished until 1930 when she arranged to have 72 of them published in Rock paintings in South Africa. The copy first printed in 1905 as 'Bushman disguised as ostrich', was also included, this time as 'Ostrich hunt'. ${ }^{2}$ Some of the plates were accompanied by explanations:

In the letterpress accompanying the reproductions all the Bushman explanations given are taken from the notes of Dr Bleek and Miss Lloyd. ${ }^{53}$

The following explanation appeared next to 'Ostrich hunt':

EXPLANATION - A Bushman said of the picture, 'Ostriches, three black males, two blue females. The "nusa Bushmen, not the 'kham Bushmen, are

48 McGregor Museum Depot MMKD 2648/2. Correspondence: Dorothea Bleek to Maria Wilman, 19 October 1944.

49 McGregor Museum Depot MMKD 2648/2. Correspondence: Dorothea Bleek to Maria Wilman, 19 October 1944.

50 GW Stow, The native races of South Africa, (Swan \& Sonnenschein, London, (1905) 1964), p. 82.

51 E Eberhard, "Wilhelm Bleek and the founding of Khoisan research", in J Deacon and TA Dowson (eds.), Voices from the past: IXam Bushmen and the Bleek and Lloyd collection, pp. 61-62.

52 GW Stow, and DF Bleek, Rock paintings in South Africa from parts of the Eastern Province and Orange Free State, Plate 21.

53 Ibid., p. xvii. 
said to hunt in ostrich skins'. ${ }^{4}$

Apart from the fact that this 'explanation' by a Bushman, supports Stow's belief in hunting disguises, it also implies that in Bleek's lifetime, he had inspected and studied an unidentified ostrich copy.

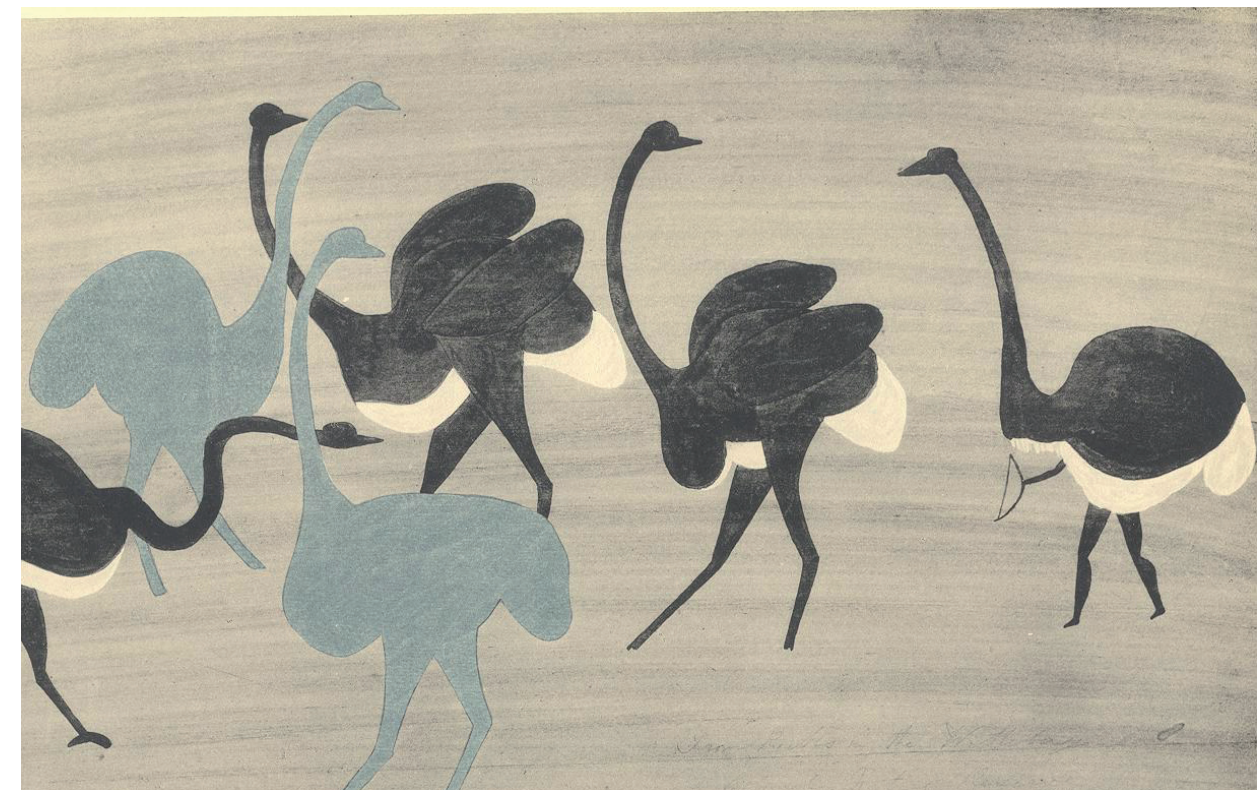

\section{Illustration 3. Ostrich hunt. Source: Stow and Bleek (1930), Plate 21.}

At the time of the 1930 publication, half a century had elapsed since Stow's death, and his copies were no longer regarded as sacrosanct. Interested persons were given access to them, and Dorothea Bleek also arranged that duplicates be made:

(I)f I ever wished to part with the duplicates I have made of Stow's copies of Bushman paintings, the McGregor Museum might like to buy them .... Most of the duplicates were made by Miss (name illegible), a few by Miss Gill. Of those made by Miss (name illegible), I have a number of the tracings she made as preliminaries .... I should also add some of Stow's preliminary tracings, or sketches ....55

This large-scale duplication of Stow's copies was no doubt motivated by a sincere desire on Dorothea Bleek's part to keep a record of the copies, and to safeguard them from possible loss at sea or elsewhere, en route to the publisher Methuen and Co. in London. Included in this letter was a list of the duplicates; she noted that a number of the 'copies' were missing but that she had the 'tracings', and that '21 (is) missing altogether'

54 Ibid., op. Plate 21.

55 McGregor Museum Depot MMKD 2648/1. Correspondence: Dorothea Bleek -Maria Wilman, 18 September 1944. 
(the blue ostriches). This puzzling remark suggests that at the time of the 1930 publication, there was neither a field copy nor a finished copy of the blue ostriches; yet a copy was included in the subsequent publication? It has always been assumed that 'Bushman disguised as ostrich' (1905), and 'Ostrich hunt' (1930) are identical. However a close scrutiny and comparison of the two versions, reveals some unexpected differences.

\section{Stylistic disparities: Bushman disguised as ostrich (1905); Ostrich hunt (1930)}

In the 1905 version of the blue ostriches, the background consists of faint, horizontal charcoal or pencil lines, and the colour application of the ostriches is flat and smooth. The most pronounced difference lies in the addition of delicate pencil shading applied over the painted areas, in order to emphasise the form of the blue female ostriches; this pencil shading is applied in a distinctly Western mode. The copy is not inscribed. ${ }^{56}$ In the 1930 version the background is washed in, ${ }^{57}$ the colour application of the ostriches is uneven, and the wings of two of the black male ostriches are clearly demarcated. The under belly of one of the blue female ostriches has a pronounced curve. The copy is not dated or signed but the location of the site is indicated in faintly visible script. Dowson et al. argue that this script appears to be that of Stow. ${ }^{58}$

This stylistic disparity of the two versions points to at least two different persons involved in their execution. The possibility that Stow himself executed the 1905 version is remote. In his personal correspondence he repeatedly stated that he was submitting only 'original sketches' i.e. unfinished field copies; his detailed list to Lucy Lloyd did not include an ostrich copy. He died before these unfinished copies could be returned to him to finish. Lucy Lloyd may have presented an unfinished field copy of ostriches to the publisher after Stow's death. If this is indeed true, an unknown person completed it in colour and added the pencil shading, no doubt thinking to enhance it. Additional pencil shading of this nature does not occur in any of Stow's copies.

Seemingly unaware of the fact that two separate versions of the blue ostriches were executed, Dowson et al. refer only to the 1930 version. ${ }^{59}$ If this 1930 version is indeed the original 'fake', executed by Stow, it must be assumed that the 1905 version is a fake of Stow's 'fake', because clearly, the two versions were not executed by the same person. The question must also be asked why it was necessary to make a fake if a perfectly

56 GW Stow, The native races of South Africa, op. p. 82.

57 GW Stow, and DF Bleek, Rock paintings in South Africa from parts of the Eastern Province and Orange Free State, Plate 21.

58 TA Dowson, PV Tobias and JD Lewis-Williams, "The mystery of the blue ostriches: clues to the origin and authorship of a supposed rock painting" in African Studies, 53(1), 1994, pp. 29-30.

59 Housed in the SA Museum, Cape Town.

$T D, 1$ (1), December 2005, pp. 43-58 
acceptable copy - the 1930 version - was available? Endless speculation is possible, but all allegations remain conjectural and unproven. In the intervening years from Stow's death (1882) to the publication of his manuscript (1905), and finally to the Stow \& Bleek publication (1930), his copies were freely inspected and copied, passed hands several times, were perused by at least three different publishers, and were transported, to and fro, between two continents. ${ }^{60}$ Under these adverse circumstances, the possibility of the original collection remaining intact is highly unlikely, and extraneous intervention after his death cannot be excluded. However, there is no evidence that points to Stow (or any other party) committing deliberate fraud.

\section{Unfounded accusations}

Not only is Stow accused of committing deliberate fraud, he is also described as a weak character with many undesirable qualities. He is slated for the many occupations he followed and the fact that none of his undertakings prospered. ${ }^{61}$ In a perceptive paragraph describing the circumstances in the Eastern Cape during this period of Stow's life Schoeman writes that

(T)his was not untypical of the career of a young English-speaking immigrant in the Eastern Cape during that period, a history of attempts and failures, financial difficulties and general improvisation. ${ }^{62}$

Schoeman refers to the many professions the historian G.M. Theal and many of their contemporaries followed:

(L)ife in the Cape Colony was as yet not particularly stable, economically or otherwise, and improvisation was the order of the day ....63

The authors of the article argue that this 'life of frustration' manifested itself in some unattractive ways and that he was regarded as 'self-centred and vain of his achievements' and that he was vain, insensitive and secretive. ${ }^{64}$ The authors argue:

(T)he biography (presumably of Young) and Stow's letters reveal him as boastful, ambitious and resentful and that he had not received sufficient recognition. ${ }^{65}$

This final accusation is difficult to understand as Stow's letters reveal

$60 \mathrm{~K}$ Schoeman, A debt of gratitude: Lucy Lloyd and the 'Bushman work' of GW Stow, pp. $109 ; 112 ; 114 ; 115 ; 116 ; 118 ; 119 ; 122$.

61 TA Dowson, PV Tobias and JD Lewis-Williams, "The mystery of the blue ostriches: clues to the origin and authorship of a supposed rock painting" in African Studies, 53(1), 1994, p. 34.

62 K Schoeman, A debt of gratitude: Lucy Lloyd and the 'Bushman work' of GW Stow, p. 43.

63 Ibid., p. 44.

64 TA Dowson, PV Tobias and JD Lewis-Williams, "The mystery of the blue ostriches: clues to the origin and authorship of a supposed rock painting" in African Studies, 53(1), 1994, p. 34. Emphasis added.

65 Ibid., p. 35. Emphasis added. 
him as a typical Victorian 'gentleman', cultured, courteous and modest, always deeply grateful for any interest shown in his work. Although his treatise was not accepted for publication in his lifetime, the value of his work was widely recognised and acknowledged by many of the most prominent citizens of the day including $\mathrm{R}$. Trimen, curator of the S.A. Museum, ${ }^{66}$ Sir John Stone, (Astronomer Royal), ${ }^{67}$ William Littleton (private secretary of Sir Bartle Frere); ${ }^{68}$ Sir Bartle Frere himself, ${ }^{69}$ Bishop Merriman, ${ }^{70}$ and J.S.B. Todd (acting executive commissioner for the Cape Colony at the Paris Exhibition of 1878), ${ }^{71}$ and numerous others. ${ }^{72}$

\section{Conclusion}

In their final 'INDICTMENT' Dowson et al. repeat their allegations and reiterate what they believe to be the motive for the forgery. They argue:

Very possibly he forged it to support his narrative view of the art.... ${ }^{73}$

This allegation is difficult to understand as Stow had a substantial number of copies depicting what he believed to be the customs and beliefs of the Bushman, including hunting disguises; there simply was no need to 'fake' such a copy. Stow's efforts to secure a publisher for his treatise (which embraced his narrative view of the art), were fully supported by W.H.I. Bleek, by Lucy Lloyd and by a small but extremely influential group that included Sir Bartle Frere, governor of the Cape Colony. ${ }^{74}$ Stow was recognised by his contemporaries as an authority, and while conflicting opinions may have been expressed in private, there was no question of animosity or public dissension. Theoretical issues and academic debate regarding the meaning and motivation of rock art would only become a burning issue, and be hotly contested, many years later with the introduction of the trance hypotheses/shamanistic approach in the 1980s. In the final analysis the defamatory article is more about two mutually exclusive interpretational approaches of rock art, than it is about an alleged forgery. In the process, irreparable harm has been done to the name of George William Stow and his contribution to rock art research and conservation. While his pioneering contribution was acknowl-

66 K Schoeman, A debt of gratitude: Lucy Lloyd and the 'Bushman work' of GW Stow, p. 63.

67 Ibid., p.70.

68 Ibid., p. 74.

69 Ibid., p. 86; 88; 91; 104.

70 Ibid., p. 69.

71 Ibid., p. 78.

72 Ibid., p. 65, 66, 69, 70, 76, 93, 94, 100.

73 TA Dowson, PV Tobias and JD Lewis-Williams, "The mystery of the blue ostriches: clues to the origin and authorship of a supposed rock painting" in African Studies, 53(1), 1994, p. 35.

74 K Schoeman, A debt of gratitude: Lucy Lloyd and the 'Bushman work' of GW Stow, pp. 70, 79, 90, 93-94, 98, 100 . 
edged by earlier researchers, ${ }^{75}$ after 1994 his entire contribution became suspect. This includes not only his copies of rock art (many of which have since become obliterated), but also the valuable information he obtained from Bushman informants regarding their art and culture.

75 E.g. I Schapera, The Khoisan peoples of South Africa: Bushmen and Hottentots, (Routledge and Kegan Paul, London, [1930], [1963]); AR Willcox, The rock art of Africa, (Croom Helm, London 1984); B Woodhouse, The rain and its creatures as the Bushmen painted them, (William Waterman, Johannesburg, 1992). 